\title{
Polarization of Myelinating Schwann Cell Surface Membranes: Role of Microtubules and the Trans-Golgi Network
}

\author{
Bruce D. Trapp, ${ }^{1}$ Grahame J. Kidd, ${ }^{2, a}$ Peter Hauer, ${ }^{2}$ Eileen Mulrenin,, ${ }^{2}$ Carol A. Haney, ${ }^{2}$ and S. Brian Andrews ${ }^{3}$ \\ ${ }^{1}$ Department of Neurosciences, The Cleveland Clinic Foundation, Cleveland, Ohio 44195, ${ }^{2}$ Department of \\ Neurology, The Johns Hopkins University School of Medicine, Neuromuscular Division, Baltimore, Maryland 21287. \\ 6965, and ${ }^{3}$ Laboratory of Neurobiology, NINDS, National Institutes of Health, Bethesda, Maryland 20892
}

\begin{abstract}
Schwann cells polarize their surface membranes into several biochemically and ultrastructurally discrete regions of the myelin internode. To form these membrane domains, Schwann cells must sort, transport, and target membrane proteins appropriately. In this study, microtubule disassembly, confocal microscopy, and electron microscopic immunocytochemistry were used to investigate mechanisms involved in targeting $P_{0}$ protein $\left(P_{0}\right)$, the myelin-associated glycoprotein (MAG), and laminin to different plasma membrane domains in myelinating Schwann cells from 35-d-old rat sciatic nerve. After microtubule disassembly by colchicine, all three proteins accumulated in Schwann cell perinuclear cytoplasm, indicating that microtubules are necessary for their transport. The distributions of Golgi membranes, endoplasmic reticulum, and intermediate filaments were also altered by colchicine treatment. Electron microscopic immunocytochemical studies indicated that $\mathbf{P}_{0}$ and MAG are sorted into separate carrier vesicles as they exit the trans-Golgi network. Following microtubule disassembly, $P_{0}$-rich carrier vesicles fused and formed myelinlike membrane whorls, whereas MAG-rich carrier vesicles fused and formed mesaxon-like membrane whorls. Microtubule disassembly did not result in mistargeting of either $P_{0}$ or MAG to surface membranes. These results indicate that following sorting in the trans-Golgi network, certain carrier vesicles are transported along the myelin internode on microtubules; however, microtubules do not appear to target these vesicles selectively to specific sites. The targeting of $P_{0^{-}}$, MAG-, and laminin-rich carrier vesicles to specific sites most likely occurs by ligand receptor binding mechanisms that permit fusion of carrier vesicles only with the appropriate target membrane.
\end{abstract}

[Key words: protein sorting, protein targeting, $P_{o}$ protein, myelin-associated glycoprotein, microtubules, myelination]

\footnotetext{
Received May 20, 1994; revised Aug. 15, 1994; accepted Aug. 22, 1994.

We thank Dr. Pamela Talalay for helpful comments, Dr. Chris Linington for $P_{0}$ monoclonal antibodies, Rod Graham for editing and preparing the manuscript, and Diana Curley for technical assistance. This work was supported by grants NS 22849 and NS 29818 from the National Institute of Neurological Disorders and Stroke. Dr. Kidd is a postdoctoral fellow of the National Multiple Sclerosis Society.

Correspondence should be addressed to Dr. Bruce Trapp, Department of Neurosciences-NC30, The Cleveland Clinic Foundation, 9500 Euclid Avenue, Cleveland, OH 44195.

Present address: Department of Biochemistry, University of Queensland, St. Lucia, Queensland, Australia 4067.

Copyright (C) 1995 Society for Neuroscience $0270-6474 / 95 / 151797-11 \$ 05.00 / 0$
}

The surface membranes of most eukaryotic cells are divided into specialized regions that have different molecular compositions and functions. Plasma membranes in cells that extend long processes can be very complex. The surface membranes of neurons, for example, can be divided into two biochemically and functionally distinct domains, axons and dendrites, both of which can be further divided into multiple subdomains. Polarization of cell surfaces into discrete regions is a complex process that must result in site-specific delivery of membrane components. Protein sorting, transport, integration, and stabilization are just a few of the mechanisms whereby cells establish unique plasma membrane domains.

Much of what is known about mechanisms of protein sorting and targeting has been obtained from in vitro studies of epithelial cells that polarize their surfaces into apical and basolateral domains (Rodriguez-Boulan and Nelson, 1989; Simons and Wandinger-Ness, 1990; Mostov et al., 1992). Epithelial cells target proteins from Golgi membranes to their correct surface domains by two pathways. In one pathway, segregation of newly synthesized glycoproteins occurs in the trans-Golgi network, where basolateral and apical proteins are sorted into separate carrier vesicles that are then targeted directly to the apical or basolateral plasma membrane domains (Rindler et al., 1984; Griffiths and Simons, 1986; Rodriguez-Boulan and Nelson, 1989). The second pathway transports both apical and basolateral proteins to the basolateral surface. Apical proteins are then removed from the basolateral membrane by endocytosis and relocated to the apical surface (Hubbard and Stieger, 1989). Different epithelial cells use these two transport pathways to different degrees (Rindler et al., 1987; Achler et al., 1989; Eilers et al., 1989; LeBivic et al., 1990; Matter et al., 1990). In many cases, specialized microtubule (MT) organizations facilitate the delivery of carrier vesicles to specific membrane domains (Hugon et al., 1987; Achler et al., 1989; Bre et al., 1990; Gilbert et al., 1991).

Schwann cells, the myelin-forming cell in the peripheral nervous system (PNS), polarize their surfaces into multiple membrane domains. Three glycoproteins $-\mathrm{P}_{0}$ protein $\left(\mathrm{P}_{0}\right)$, the myelin-associated glycoprotein (MAG), and laminin-are synthesized in rough endoplasmic reticulum (RER), processed through the Golgi, and then targeted to different Schwann cell surface membranes: $\mathrm{P}_{0}$ to compact myelin (Trapp et al., 1981), MAG to noncompact myelin (Trapp and Quarles, 1982), and laminin to the plasma membrane (Cornbrooks et al., 1983). Myelin basic protein (MBP) is targeted to compact myelin by translocation of its mRNA (Colman et al., 1982; Trapp et al., 1987). The outer perimeter of the myelin internode consists of cyto- 
plasmic-rich and cytoplasmic-free regions (Mugnaini et al., 1977; Trapp et al., 1989b). The cytoplasmic-rich regions form channels that extend along the entire length of the internode. Proteins, lipids, and RNA are transported from the perinuclear cytoplasm to points along the internode within these channels (Gould and Mattingly, 1990). Microtubules are abundant in these channels (Peters et al., 1991; Kidd et al., 1994) and they probably help transport myelin proteins along the myelin internode.

The present study investigates how $P_{0}, M A G$, and laminin are sorted, transported, and targeted to different membrane domains. By using colchicine to reversibly depolymerize Schwann cell MTs in vivo, this study demonstrates that $\mathrm{P}_{0}, \mathrm{MAG}$, and laminin are sorted into separate carrier vesicles as they exit the transGolgi network. These vesicles are transported along the myelin internode on MTs, and then inserted directly into the appropriate surface membrane domain. Our data also demonstrate that MTs maintain the distribution of Golgi membranes as well as networks of smooth endoplasmic reticulum (SER) and intermediate filaments that extend along the outer perimeter of the myelin internode.

\section{Materials and Methods}

\section{Colchicine administration}

Sprague-Dawley rats ( $35 \mathrm{~d}$ old) were anesthetized and the left sciatic nerve was immobilized in the midthigh. Two milligrams of rayon wool (obtained from sterile gauze pads) soaked in $20 \mu \mathrm{l}$ of colchicine was placed around the nerve. Care was taken not to constrict the nerve at either end of the rayon wool cuff. After $2 \mathrm{hr}$, the cuff was removed and the animal was allowed to recover. Rayon wool cuffs soaked in $20 \mu \mathrm{l}$ of saline were placed around the right sciatic nerves, which then served as sham-operated controls. Colchicine was applied to the rayon wool cuffs at concentrations of $1 \mathrm{mM}, 5 \mathrm{mM}, 7.5 \mathrm{~mm}$, and $10 \mathrm{~mm}$. Colchicineand saline-treated nerves were analyzed at 6,12 , and $24 \mathrm{hr}$, and at $7 \mathrm{~d}$ after cuff removal.

\section{Light microscopic immunocytochemistry}

Rats were anesthetized and killed by intercardiac perfusion with $4 \%$ paraformaldehyde and $0.08 \mathrm{M}$ phosphate buffer. The segments of nerves covered by the rayon wool cuff were removed, teased into individual nerve fibers, and stained by indirect immunofluorescence procedures. In brief, nerve fibers were permeabilized in Triton $X-100$, washed in phosphate-buffered saline (PBS), and incubated overnight at $4^{\circ} \mathrm{C}$ in primary antibodies diluted with PBS. Monoclonal and/or polyclonal anti bodies to $\mathrm{P}_{0}$ (Trapp et al., 1981), MAG (Trapp et al., 1989a), laminin (Sigma, St. Louis, MO), myelin basic protein (MBP) (Trapp et al., 1987), endoplasmic reliculum (Louvard et al., 1982), and vimentin (Sigma) were used. The fibers were washed in PBS and then incubated for $2 \mathrm{hr}$ in secondary antibodies conjugated with either fluorescein or Texas red. After further washing in PBS, the teased tibers were placed on slides in a Mowiol-based mounting medium [10\% Mowiol (Calbiochem; La Jolla, CA), $0.15 \%$ paraphenylenediamine (Sigma) in PBS at $\mathrm{pH} 8.0 \mathrm{l}$ and overlaid with coverslips. Teased fibers were imaged with a Bio-Rad MRC 600 confocal scanning laser microscope, as described previously (Kidd et al., 1994). The resulting optical sections were $\sim 1.5$ $\mu \mathrm{m}$ thick and were the average of $8-10$ frame scans.

\section{Electron microscopic analysis}

Rats were anesthetized and perfused with $4 \%$ paraformaldehyde, $2.5 \%$ glutaraldehyde, and $0.08 \mathrm{M}$ phosphate buffer.

Epon sections. Colchicine- and saline-treated nerves were postfixed in $2 \% \mathrm{OsO}_{4}$ at $4^{\circ} \mathrm{C}$ for $2 \mathrm{hr}$, and processed to Epon by standard procedures. One-micron-thick sections were stained with toluidine blue; ultrathin sections were stained with uranyl acetate and lead citrate. The $1 \mu \mathrm{m}$ sections were examined in a Zeiss Axiophot photomicroscope; ultrathin sections were examined in a Hitachi H-600 electron microscope.

Electron microscopic immunocytochemistry. Segments of colchicineand saline-treated nerves were removed, cut into 2-mm-long segments, infiltrated with $2.3 \mathrm{M}$ sucrose and $30 \%$ polyvinylpyrrolidone, placed on specimen stubs, and frozen in liquid nitrogen. Immunogold staining was performed by previously described modifications (Trapp et al., 1988a 1989a,b) of standard immunogold procedures (Slot and Geuze, 1984; Tokuyasu, 1986). In brief, ultrathin cryosections $(\sim 120 \mathrm{~nm}$ thick $)$ were cut on glass knives in a ultracryomicrotome (Ultracut FC4; Reichert Scientific Instruments) maintained at $-110^{\circ} \mathrm{C}$. The sections were placed on carbon- and Formvar-coated grids, immunostained, and then placed on $2.5 \%$ glutaraldehyde and PBS for $15 \mathrm{~min}$ and rinsed. The sections were subsequently stained with uranyl acetate and embedded in $1 \%$ methyl cellulose containing 3\% uranyl acetate. Immunostained cryosections were examined in a Hitachi H-600 electron microscope.

\section{Results}

The present study depends on MT disassembly, a strategy that has been instrumental in delineating the function of MTs in a variety of cell types (Rogalski and Singer, 1984; Rindler et al., 1987; Achler et al., 1989; Gilbert et al., 1991). Microtubules can be disassembled by a variety of methods, including exposure to depolymerizing drugs (colchicine, colcemid, nocodazole), low temperature, and hypertonic shock. Nocodazole is currently the most widely used drug for inducing MT disassembly in vitro, but it did not penetrate into sciatic nerves when applied by cuff. In contrast, consistent reversible MT disassembly was produced by soaking rayon wool cuffs with $20 \mu \mathrm{l}$ of $5 \mathrm{~mm}$ colchicine and placing them around the sciatic nerve for $2 \mathrm{hr}$. Colchicine concentrations higher than $5 \mathrm{~mm}$ caused Wallerian degeneration. The appropriate colchicine concentration for producing reversible MT disassembly can vary, however, depending on the supplier and the batch of colchicine.

\section{Effects of colchicine on the distribution of Schwann cell organelles}

By 24 hr after cuff removal, the light microscopic appearance of colchicine-treated nerves differed significantly from that of saline-treated nerves. Compared to saline-treated nerves (Fig. $1 A$ ), colchicine-treated nerves (Fig. $1 B$ ) had increased endoneurial area and Schwann cells of myelinated fibers had enlarged perinuclear cytoplasm. Many axons in the colchicine-treated nerves were deformed, and redundant loops of myelin were present both inside and outside the normal myelin sheath (Fig. $1 B$ ). By $7 \mathrm{~d}$ after cuff removal, however, the light microscopic appearances of saline-treated (Fig. 1C) and colchicine-treated (Fig. $1 D$ ) nerves were indistinguishable from one another.

The distribution and appearance of organelles in colchicinetreated Schwann cells differed substantially from those of salinetreated Schwann cells. Microtubules, a common constituent of Schwann cell cytoplasm in saline-treated nerves, were rare in colchicine-treated Schwann cells 12 or $24 \mathrm{hr}$ after cuff removal, although they were detected in some axons. Cytoplasmic organ elles in colchicine-treated Schwann cells showed a number of alterations that were apparent by $6 \mathrm{hr}$ and prominent by $24 \mathrm{hr}$ after cuff removal. By 6 hr, Golgi cisternae showed mild vacuolization and disruption (Fig. $2 A$ ) and an abnormally large number of small round vesicles clustered close to Golgi protiles (Fig. $2 A$, arrowheads). By $24 \mathrm{hr}$, Golgi profiles could not be identified in most Schwann cells; instead, membranous profiles that included disrupted Golgi membranes and newly synthesized but untransported membranes had accumulated in the perinuclear cytoplasm of myelinating Schwann cells (Fig. $2 B$ ).

The appearance of rough endoplasmic reticulum (RER) was also altered by colchicine treatment. Changes apparent by $6 \mathrm{hr}$ (Fig. 2A) and prominent by 24 hr (Fig. $2 B$ ) included increased numbers of ribosomes associated with the endoplasmic reticulum and alterations in the shape of the RER cisternae. Many 

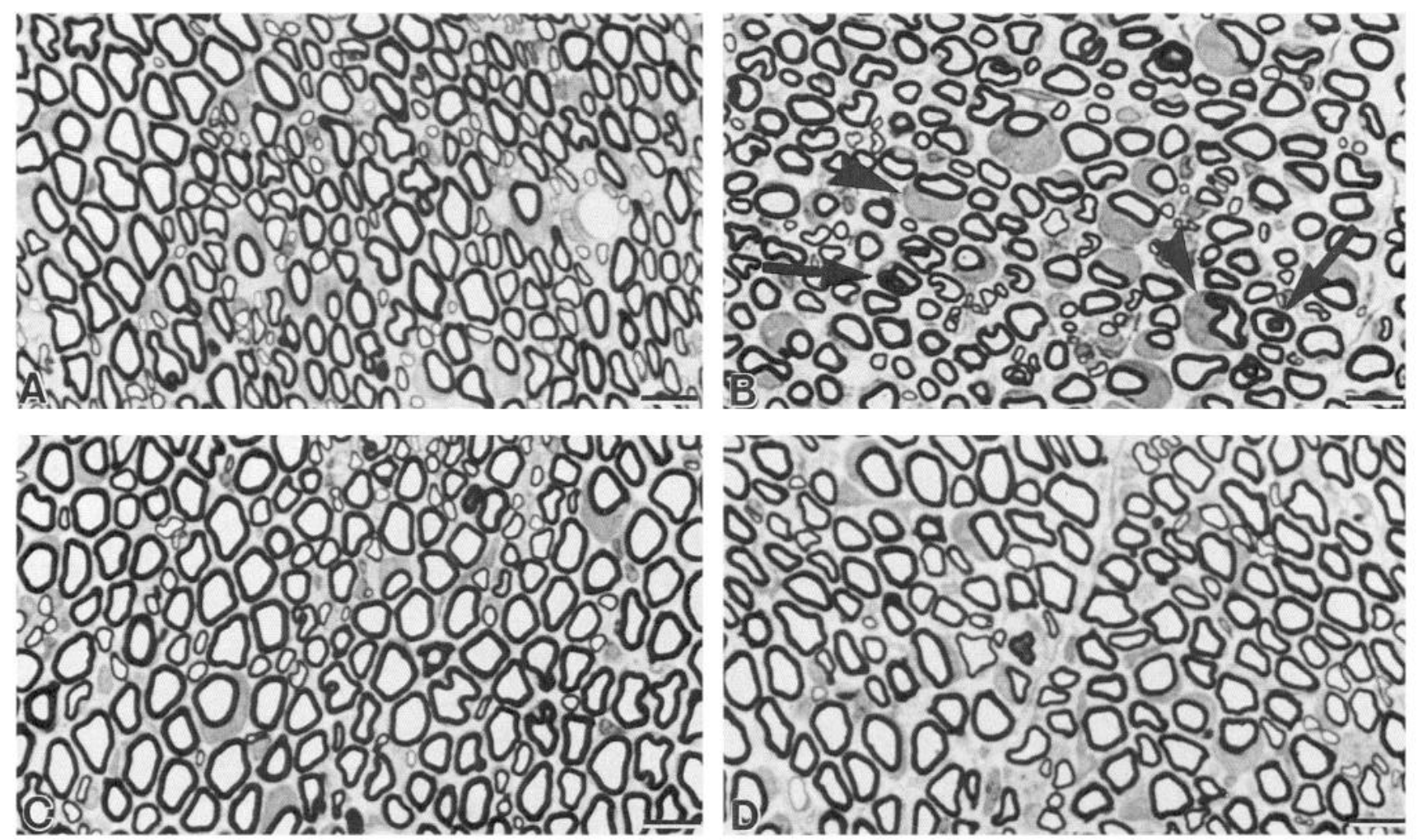

Figure 1. Light micrographs of rat sciatic nerves examined $1 \mathrm{~d}(A, B)$ and $7 \mathrm{~d}(C, D)$ after saline $(A, C)$ or colchicine $(B, D)$ treatment. Saline treatment had no detectable effect on the light microscopic appearance of rat sciatic nerve $(A, C)$. In contrast, $1 \mathrm{~d}$ after colchicine treatment, Schwann cell perinuclear cytoplasm was hypertrophied $(B$, arrowheads) and some myelin internodes contained redundant loops of myelin $(B$, arrows). These colchicine-induced changes were reversible and not detected $7 \mathrm{~d}$ after colchicine treatment $(D)$. Scale bars, $10 \mu \mathrm{m}$.

RER cisternae were condensed, shortened, and tightly packed by $6 \mathrm{hr}$ after colchicine cuff removal (Fig. 2A, large arrows). Distended circular profiles of RER (Fig. $2 A$, small arrow) were occasionally seen by $6 \mathrm{hr}$ after cuff removal and were prominent by $24 \mathrm{hr}$.

Colchicine-treated nerves also contained aggregates of tightly packed membranes in perinuclear cytoplasm (Fig. $2 B$, arrowheads) as well as in the cytoplasmic channels located at the outer margin of myelin internodes (Fig. 2C,D). Membrane aggregates present by $12 \mathrm{hr}$ after cuff removal (Fig. $2 C$ ) were not as extensive or tightly packed as those found after $24 \mathrm{hr}$ (Fig. 2B,D). Mitochondria, multivesicular bodies, intermediate filaments, and occasional lipid droplets often surrounded these membrane stacks.

To characterize immunocytochemically the membrane stacks that accumulated after MT disassembly, saline- and colchicinetreated nerves were double labeled for endoplasmic reticulum (ER) and intermediate filaments, and examined by confocal microscopy. In Schwann cells from saline-treated nerves, ER (Fig. $3 A$ ) and vimentin (Fig. $3 B$ ) immunoreactivity extended from the perinuclear cytoplasm into and all along the cytoplasmic channels at the outer margin of the myelin internode, demonstrating extensive ER and intermediate filament networks. Twenty-four hours after colchicine treatment, ER (Fig. $3 C$ ) and vimentin (Fig. $3 D$ ) immunoreactivity had condensed into solid patches and/or rings. In cells that were double labeled for ER and vimentin, three-dimensional reconstructions from serial confocal images ( $\mathrm{Z}$ series) indicated that ER-positive patches were surrounded by vimentin staining. To extend these light microscopic studies, ultrathin cryosections of saline- and colchicine-treated nerves were double labeled with vimentin and ER antibodies. In salinetreated nerves, vimentin and ER immunoreactivity was randomly distributed throughout Schwann cell cytoplasm (data not shown). The stacks of ER membranes that accumulated after MT disassembly were labeled by the ER antibody (Fig. $3 E ; 10 \mathrm{~nm}$ gold). Vimentin immunoreactivity (Fig. $3 E ; 5 \mathrm{~nm}$ gold) surrounded, but rarely was detected within, the ER-positive membrane stacks. The membrane stacks were not stained by $\mathrm{P}_{0}$, MAG, or laminin antibodies (data not shown).

\section{Distribution of myelin proteins}

To investigate the role of MTs in intercellular transport, teased nerve fibers from saline- and colchicine-treated nerves were stained with $\mathrm{P}_{0}, \mathrm{MAG}$, laminin, and MBP antibodies and analyzed by confocal microscopy (Fig. 4). In saline-treated nerves, $\mathrm{P}_{0}$ antiserum stained portions of compact myelin and regions of Schwann cell perinuclear cytoplasm (Fig. $4 A$ ). Perinuclear staining was particulate and has been shown previously to be Golgi staining (Trapp et al., 1981). By $24 \mathrm{hr}$ after colchicine cuff removal, $\mathrm{P}_{0}$ protein had accumulated in the perinuclear cytoplasm of myelinating Schwann cells (Fig. 4B). Colchicine treatment caused less dramatic increases in perinuclear MAG immunoreactivity (data not shown). Laminin, a constituent of Schwann cell basal lamina, was barely detectable in Schwann cell perinuclear cytoplasm of 35-d-old saline-treated nerves (Fig. 4C), but did accumulate in Schwann cell perinuclear cytoplasm after MT disassembly (Fig. 4D). Myelin basic protein, an extrinsic membrane protein enriched in compact myelin, was weakly de- 

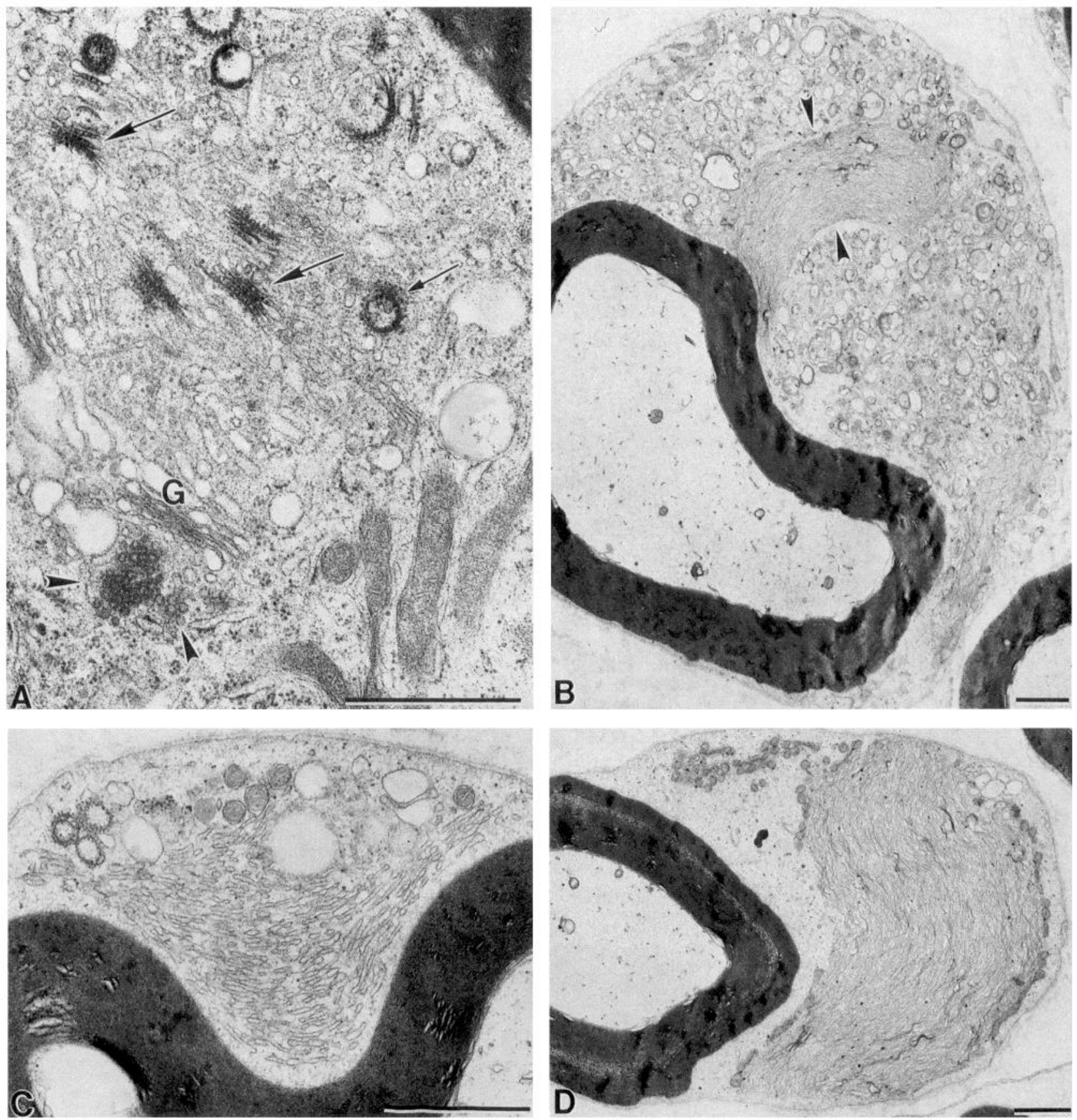

Figure 2. Electron micrographs of myelinated Schwann cells from sciatic nerves examined $6(A), 12(C)$, and $24(B, D)$ hr after colchicine treatment. By $12 \mathrm{hr}$, microtubules are not detected, rough endoplasmic reticulum membranes form irregular profiles $(A$, arrows), and aggregates of small vesicles $(A$, arrowheads) accumulate near distended Golgi cisternae $(G)$. Twenty-four hours after colchicine treatment, a marked accumulation of membrane profiles fill the swollen Schwann cell perinuclear cytoplasm and islands of tightly packed membranes appear (B, arrowheads). These islands of membranes were also detected in the cytoplasmic channels located at the outer perimeter of the myelin sheath $(C, D)$; membranes were packed closer at $24 \mathrm{hr}(D)$ than at $12 \mathrm{hr}(C)$. Scale bars, $1 \mu \mathrm{m}$.

tectable in myelinating Schwann cell perinuclear cytoplasm in both saline- (Fig. 4E) and colchicine-treated (Fig. 4F) nerves. These data indicate that intact MTs are necessary for transporting $\mathrm{P}_{0}$, MAG, and laminin along the myelin internode.

The subcellular distributions of $\mathrm{P}_{0}$ and MAG were determined in ultrathin cryosections of saline- and colchicine-treated nerves by immunogold procedures. In Schwann cell perinuclear cytoplasm from saline-treated nerves, $\mathrm{P}_{0}$ protein was closely associated with Golgi membranes and was abundant in compact my- elin (Fig. 5A). $\mathrm{P}_{0}$ antibodies labeled small vesicles associated with the trans-Golgi network (Fig. $5 A$, arrowheads); they also labeled vesicles within the cytoplasmic channels at the outer perimeter of the myelin internode (Fig. 5B, arrowheads). These results support the hypothesis that $\mathrm{P}_{0}$ protein is transported to compact myelin in membrane vesicles that bud from the transGolgi network.

In perinuclear cytoplasm of Schwann cells from nerves obtained $24 \mathrm{hr}$ after colchicine treatment, abundant $\mathrm{P}_{0}$ immu- 

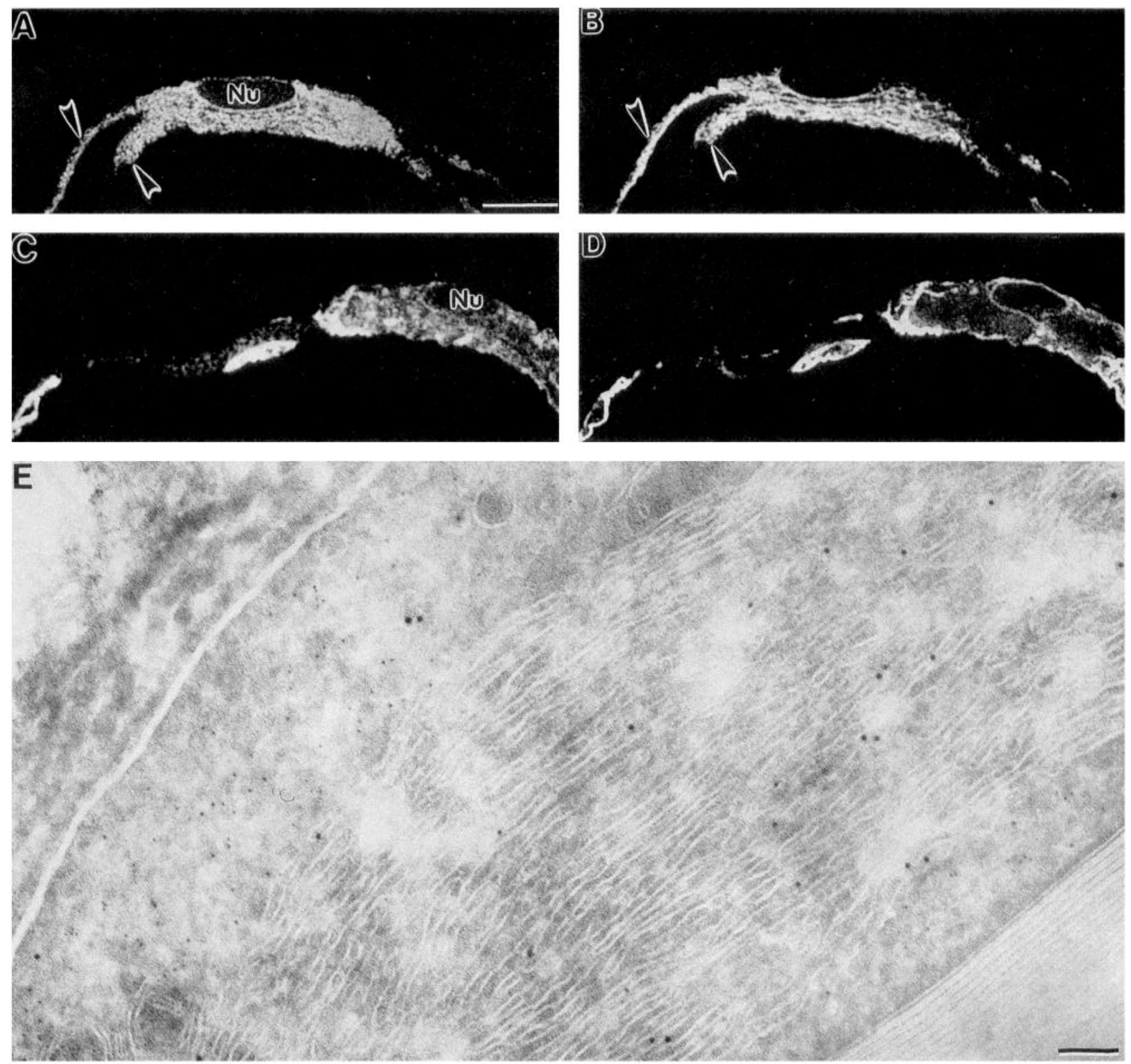

Figure 3. Light and electron microscopic distribution of endoplasmic reticulum $(A, C)$ and vimentin $(B, D)$ in saline- $(A, B)$ and colchicine-treated $(C-E)$ nerves. In double-labeled confocal images from normal myelinated fibers, endoplasmic reticulum $(A)$ and intermediate filaments $(B)$ are evenly distributed throughout Schwann cell perinuclear cytoplasm and the cytoplasmic channels (arrowheads) located at the outer perimeter of the myelin internode. Microtubule disassembly condenses the endoplasmic reticulum $(C)$ and vimentin $(D)$ immunoreactivity into small islands. Double labeling of ultrathin cryosections ( $E$; vimentin labeled by $5 \mathrm{~nm}$ gold; endoplasmic reticulum labeled by $10 \mathrm{~nm}$ gold) shows that these islands contain a central core of endoplasmic reticulum surrounded by intermediate filaments. $N u$, nucleus. Scale bars: $A-D, 10 \mu \mathrm{m} ; E, 0.1 \mu \mathrm{m}$.

nolabeling was closely associated with small round vesicles, larger, more irregularly shaped vesicles, and membrane whorls (Fig. $5 C, D$ ). Other vesicles and membranes in perinuclear cytoplasm were not labeled by $\mathrm{P}_{0}$ antibodies. In colchicine-treated nerves, $\mathrm{P}_{0}$-positive vesicles and membrane profiles were abundant only in Schwann cell perinuclear cytoplasm and were not found in the Schwann cell cytoplasmic channels along the outer margin of the myelin internode. These observations indicate that the perinuclear membrane whorls resulted from accumulation of newly synthesized $\mathrm{P}_{0^{-}}$ positive membranes rather than from degenerative changes of previously formed myelin.
The build-up of $P_{0}$ transport vesicles in Schwann cell perinuclear cytoplasm allowed investigation of membrane targeting of $\mathrm{P}_{0}$ protein. In perinuclear regions of myelinating Schwann cells, colchicine treatment did not increase $\mathrm{P}_{0}$ labeling of the Schwann cell plasma membrane or outer mesaxon. In perinuclear cytoplasm, however, myelin-like whorls were labeled intensely by $\mathrm{P}_{0}$ antibodies (Fig. $5 D$, arrowheads), indicating that $\mathrm{P}_{0}$-rich transport vesicles can fuse with one another. These myelin-like whorls were detected only in perinuclear cytoplasm and not in the cytoplasmic channels that extend along the myelin internode. The lamellar spacing of these $\mathrm{P}_{0}$-positive membrane whorls differed slightly from that of compact myelin. Occasional mem- 

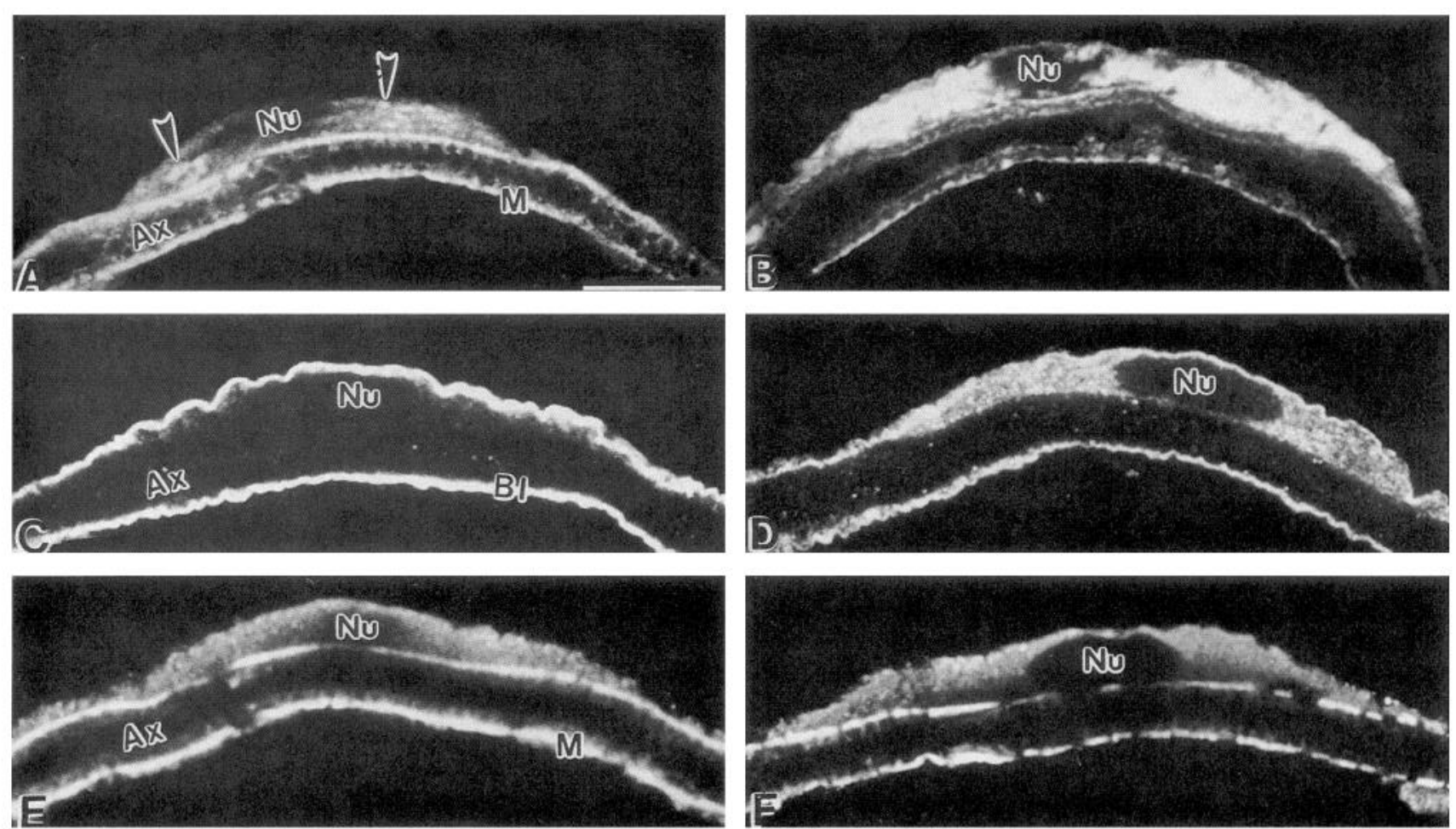

Figure 4. Confocal images of the distribution of $\mathrm{P}_{0}$ protein $(A, B)$, laminin $(C, D)$, and myelin basic protein $(E, F)$ in saline- $(A, C$, $E)$ and colchicine-treated nerves $(B, D, F)$. In saline-treated nerves, $\mathrm{P}_{0}$ antibodies stain regions of compact myelin and Golgi membranes located in perinuclear cytoplasm $(A$, arrowheads), laminin antibodies stain the basal lamina that surrounds the myelin internode $(C)$, and myelin basic protein antibodies stain regions of compact myelin and Schwann cell perinuclear cytoplasm $(E)$. After microtubule disassembly, $\mathrm{P}_{0}(B)$ and laminin $(D)$ immunoreactivity, but not myelin basic protein $(F)$ immunoreactivity, are increased within perinuclear regions of myelinating Schwann cells. $N u$, nucleus; $M$, myelin; $B l$, basal lamina. Scale bars, $10 \mu \mathrm{m}$.

brane profiles apposed compact myelin and formed a major dense line (Fig. $5 E$, arrowheads).

In ultrathin cryosections of saline-treated nerves, MAG antibodies produced little labeling of Schwann cell perinuclear cytoplasm (data not shown). Twenty-four hours after colchicine treatment, however, significant MAG immunoreactivity was detected in Schwann cell perinuclear cytoplasm (Fig. 6A). Similar to $\mathrm{P}_{0}$ immunoreactivity, cytoplasmic MAG staining in colchicine-treated nerves was restricted to perinuclear regions and was absent from the cytoplasmic channels along the myelin internode. The specificity of this cytoplasmic MAG immunoreactivity was demonstrated by the absence of compact myelin labeling and by significant labeling of the periaxonal membrane (Fig. 6A, arrowheads) and the outer mesaxon membrane (Fig. 6A, arrows). The gold particles detected in Schwann cell perinuclear cytoplasm were clustered around small vesicles and occasionally over larger membranous structures (Fig. 6B, arrows). These MAG-positive vesicles and membrane whorls were detected only in perinuclear cytoplasm, implying that they result from synthetic build-up and not from degeneration of previously formed membranes. The larger membrane whorls are most likely formed by the fusion of untransported MAG-rich vesicles. MAG antibodies did not label the Schwann cell plasma membrane or the outermost compact myelin lamella in either saline- or colchicine-treated nerves.

To investigate the possibility that $P_{0}$ and MAG are sorted into different transport vesicles as they exit the trans-Golgi network, ultrathin cryosections from colchicine-treated nerves were double labeled for $\mathrm{P}_{0}$ and MAG. By $12 \mathrm{hr}$ after colchicine treatment, both $\mathrm{P}_{0}$ and MAG immunoreactivity were present in doublelabeled cryosections (Fig. 7). Many vesicles associated with Golgi membranes were labeled by either $5 \mathrm{~nm}\left(\mathrm{P}_{0}\right)$ or $10 \mathrm{~nm}$ (MAG) gold particles (Fig. 7A,B). $\mathrm{P}_{0}$-stained vesicles were more abundant than MAG-stained vesicles, which was expected since $\mathrm{P}_{0}$ is much more abundant than MAG in peripheral nerve myelin (50\% vs. $0.1 \%$ of total protein; Figlewicz et al., 1981). MAGand $\mathrm{P}_{0}$-stained vesicles were of various sizes and shapes. The perinuclear cytoplasm of 15 Schwann cells from nerves harvested $12 \mathrm{hr}$ after colchicine treatment was photographed and the numbers of $\mathrm{P}_{0}$-positive, MAG-positive, and $\mathrm{P}_{0}$ and MAGpositive vesicles were counted. A total of 496 gold-labeled vesicular structures were identified (large multilamellar membrane whorls were excluded); 389 (78\%) of these were $\mathrm{P}_{0}$ positive, 96 (19\%) were MAG positive, and $11(2 \%)$ were positive for both $\mathrm{P}_{0}$ and MAG. Sixty-two percent of the $\mathrm{P}_{0}$-positive vesicles contained two or more gold particles, whereas $26 \%$ of MAG-positive vesicles contained two or more gold particles. These results demonstrate that two antigens in the same vesicle can be labeled and that the lack of $\mathrm{P}_{0}-\mathrm{MAG}$ double-labeled vesicles was not due to technical problems.

The membrane whorls with compact myelin-like appearance that were abundant by $24 \mathrm{hr}$ after cuff removal were labeled by $\mathrm{P}_{0}$ antiserum but not by MAG antibodies (Fig. $7 C$ ). Membrane whorls that had a greater spacing between apposing membranes were labeled by MAG antibodies but not by $\mathrm{P}_{0}$ antibodies (Fig. $7 D$ ). In all cases, the specificity of immunoreactivity in these double-labeling experiments was demonstrated by labeling of compact myelin by $\mathrm{P}_{0}$ antiserum and by labeling of outer mes- 

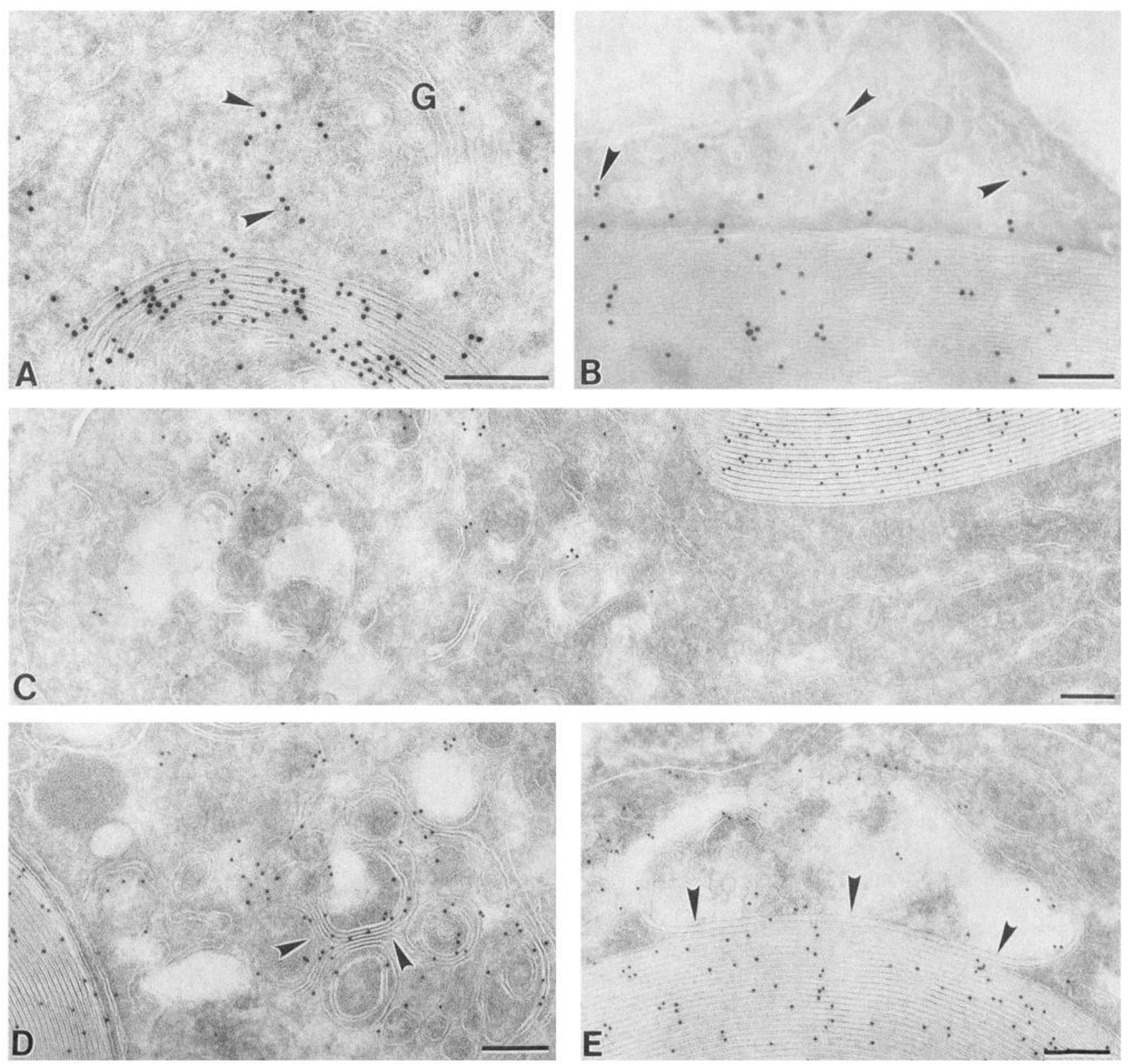

Figure 5. Immunocytochemical distribution of $\mathrm{P}_{0}$ protein in ultrathin cryosections of saline- $(A, B)$ and colchicine-treated $(C-E)$ Schwann cells obtained by immunogold $(10 \mathrm{~nm})$ procedures. In normal Schwann cells, $\mathrm{P}_{0}$ antibodies label compact myelin, Golgi membrane $(G)$, and vesicles located in perinuclear cytoplasm $(A$, arrowheads) and in the cytoplasmic channels at the outer perimeter of the myelin internode $(B$, arrowheads). Many of the membrane profiles that accumulate in Schwann cell perinuclear cytoplasm after microtubule disassembly are labeled by $\mathrm{P}_{0}$ antibodies $(C, D)$. Some appear as small vesicles, others as larger membrane whorls. Some $\mathrm{P}_{0}$-positive membranes form myelin-like structures $(D, a r r o w h e a d s)$, whereas others fuse with the myelin sheath and form an additional major dense line (E, arrowheads). Scale bars, $0.2 \mu \mathrm{m}$.

axon, Schmidt-Lanterman incisure membranes, and periaxonal membranes by MAG antibodies.

\section{Discussion}

The present study establishes that the MTs that extend along the outer perimeter of the myelin internode have two distinct functions: they translocate $P_{0}$, MAG, and laminin to their specific membrane targets; and they help organize the distribution of other organelles. The compartmentalization of $P_{0}$ and MAG in perinuclear cytoplasm after MT disassembly, and studies that have characterized MTs in myelinating Schwann cells (Kidd et al., 1994), provide additional information about how $P_{0}$ and
MAG are sorted, targeted, and inserted into different surface membranes. Whereas most MT disassembly studies have used in vitro systems (Rogalski and Singer, 1984; Rindler et al., 1987; Achler et al., 1989; Gilbert et al., 1991), the present study investigated the affects of MT disassembly on myelinating Schwann cells in vivo because axonal influences dramatically affect the distribution and organization of Schwann cell MTs (G. J. Kidd and B. D. Trapp, unpublished observation) as well as the expression of myelin protein genes (Trapp et al., 1988b).

Microtubules and organelle distribution

Our results show that MTs help to organize the distribution of Golgi membranes, endoplasmic reticulum, and intermediate fil- 

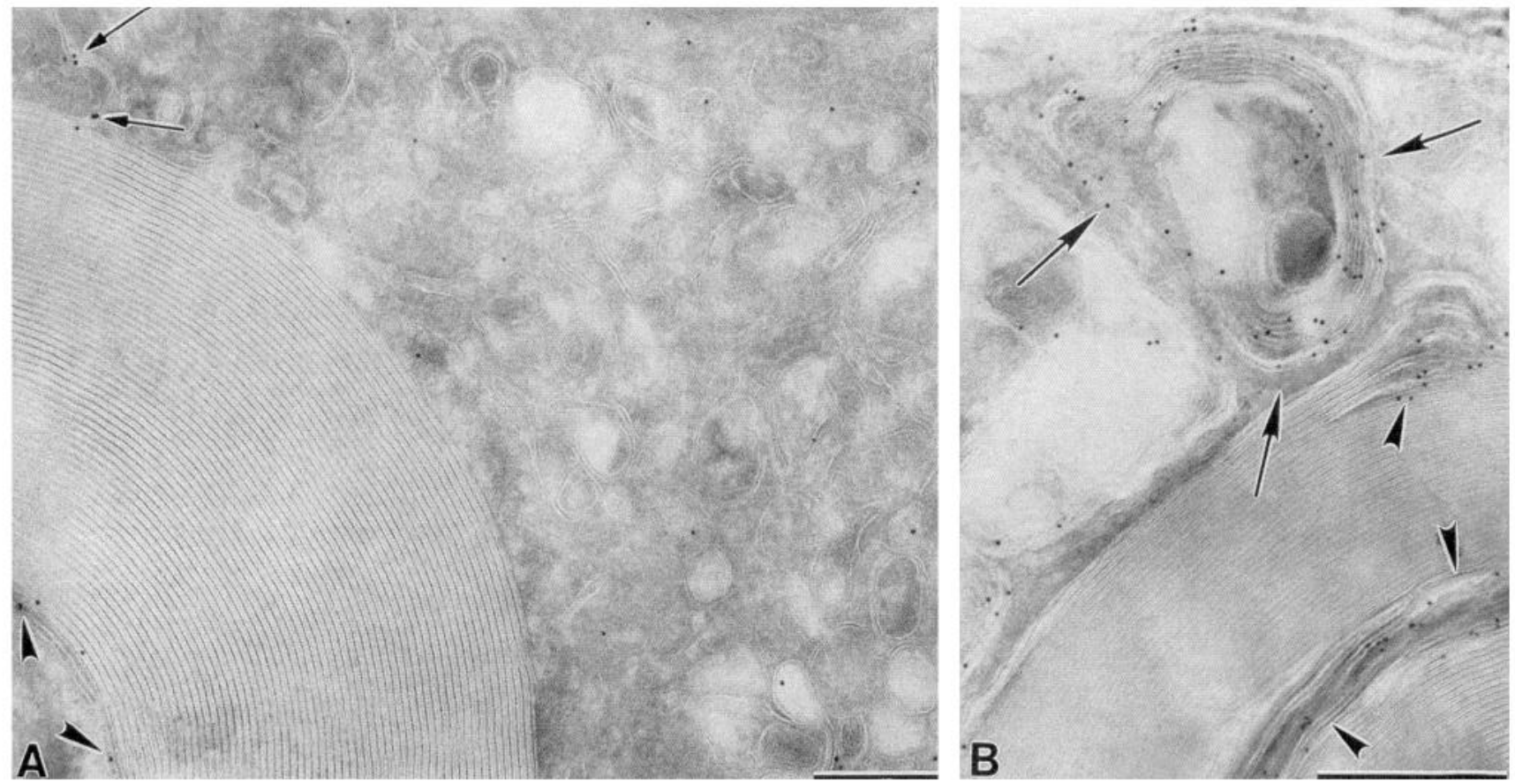

Figure 6. Immunocytochemical distribution of MAG in ultrathin cryosections of colchicine-treated Schwann cells using immunogold procedures. MAG antibodies label periaxonal $(A$, arrowheads) and outer mesaxon $(A$, arrows) membranes, but not compact myelin. Some membrane profiles that accumulate in perinuclear cytoplasm following microtubule disassembly are also labeled $(A)$. Schmidt-Lanterman incisures $(B$, arrowheads) and MAG-positive mesaxon-like membranes $(B$, arrows) were present in regions of perinuclear cytoplasm. Scale bars: $A, 0.1 \mu \mathrm{m} ; B, 0.5 \mu \mathrm{m}$.

aments in myelinating Schwann cells; this is consistent with previous reports that studied MT disassembly in a variety of cell types (Rogalski and Singer, 1984; Terasaki et al., 1986; Lee et al., 1989), including Schwann cells (Jacobs et al., 1972). Although MT disassembly disrupted the normal organization of rough endoplasmic reticulum and Golgi membranes, these membranes retained functional integrity in that they continued to synthesize $\mathrm{P}_{0}, \mathrm{MAG}$, and laminin. In the cytoplasmic channels located at the outer margin of the myelin internode, MT disassembly segregated the cytoplasmic channels into organellefree and organelle-rich regions. The organelle-rich regions were further organized into a central core of smooth endoplasmic reticulum (SER) membranes that were surrounded by intermediate filaments. The intermediate filaments did not intermingle with the SER cisternae. Mitochondria, lysosomes, endosomes, and rough endoplasmic reticulum were embedded in the intermediate filament-rich zone and excluded from the smooth endoplasmic reticulum-rich zone. This implies that the SER and intermediate filaments form separate but interconnected networks that extend from the perinuclear cytoplasm to the paranodal cytoplasm.

The extension of smooth endoplasmic reticulum throughout the cytoplasmic channels of the myelin internode is important to myelin formation. Previous studies have demonstrated that certain lipids are synthesized in the SER of these channels (Gould and Sinatra, 1981; Gould et al., 1987). The interdependence between MTs and the extension of the SER may help coordinate the insertion of lipids and Golgi-derived vesicles into various surface membranes.

\section{Microtubules and protein transport in myelinating Schwann cells}

A second role for MTs in myelinating Schwann cells is directed transport. The colchicine-induced accumulation of $\mathrm{P}_{0^{-}}, \mathrm{MAG-}$, and laminin-rich vesicles provides evidence that these proteins are transported on MTs from perinuclear cytoplasm to sites along the myelin internode. The rate of myelin deposition in 35d-old sciatic nerve is active and just below the peak rates observed at postnatal day 21 (Lemke and Axel, 1985; Trapp et al., 1988 b). $P_{0}$ accumulation in Schwann cell cytoplasm after microtubule disassembly greatly exceeds the rate of MAG accumulation because the synthetic demand for $\mathrm{P}_{0}$, which comprises $50 \%$ of total myelin protein, greatly exceeds that for MAG, which comprises $0.1 \%$ of the total myelin protein (Figlewicz et al., 1981). In contrast, myelin basic protein (MBP) did not accumulate in Schwann cell perinuclear cytoplasm after MT disassembly because targeting of MBP to myelin occurs by translocation of MBP mRNA (Colman et al., 1982; Trapp et al., 1988b; Griffiths et al., 1989). Schwann cell microtubules, however, may play a role in targeting MBP by translocating MBP mRNA and/or ribosomes along the internode (Colman et al., 1982; Gould and Mattingly, 1990).

Although the mechanisms of MT-directed transport in Schwann cells remain to be determined, these results suggest some plausible hypotheses. Microtubules in the transport channels that extend along the myelin internode have a mixed polarity; $75 \%$ have + ends pointed away from the nucleus, whereas the remaining $25 \%$ have + ends pointed toward the nucleus (Kidd et al., 1994). Microtubule-dependent transport could in principle use motors specific for either MT orientation. The absence of microtubule organizing centers in the transport channels along the myelin internode (Kidd et al., 1994) makes it unlikely that minus end-directed transport vectorially guides carrier vesicles to specific sites. It is possible that $\mathrm{P}_{0^{-}}, \mathrm{MAG}-$, and lamininrich carrier vesicles are transported along the myelin internode by the same MTs, and that site-specific targeting is regulated by special docking mechanisms. Transport within some cytoplasmic 

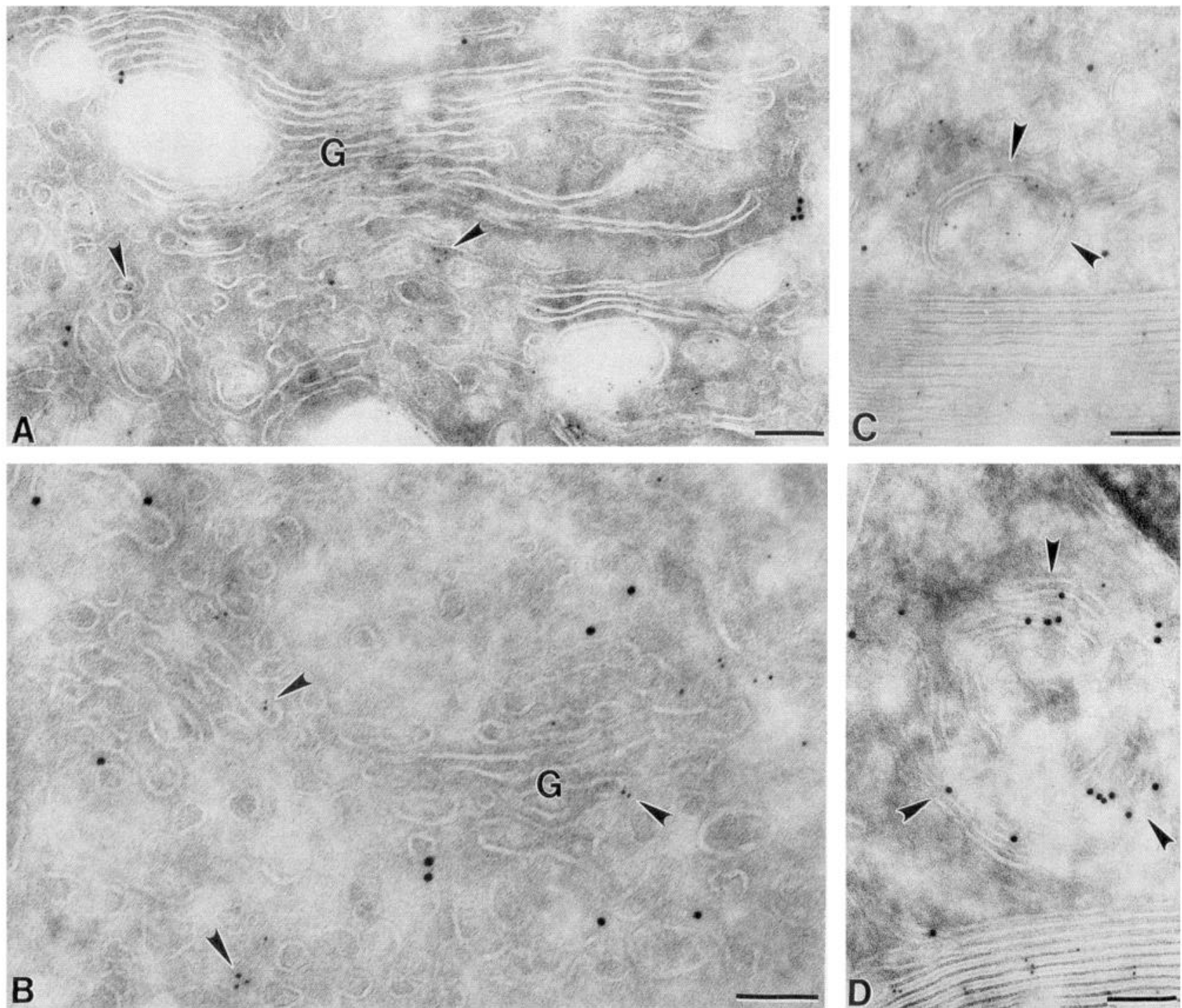

Figure 7. Ultrathin cryosections from colchicine-treated nerves double labeled with $\mathrm{P}_{0}(5 \mathrm{~nm}$ gold) and MAG (10 nm gold) antibodies. Twelve hours after colchicine treatment $(A, B)$, vesicles associated with Golgi stacks $(G)$ are labeled by either $\mathrm{P}_{0}$ or MAG antibodies. Arrowheads highlight some of the $5 \mathrm{~nm}$ gold particles. Twenty-four hours after colchicine treatment, membrane whorls are labeled with either $\mathrm{P}_{0}(C$, arrowheads $)$ or MAG $(D$, arrowheads) antibodies, but rarely with both. Scale bars, $0.1 \mu \mathrm{m}$.

domains of the myelin internode is restricted, however, in that $\mathrm{P}_{0}$-rich carrier vesicles and ribosomes are not transported into Schmidt-Lanterman incisures or periaxonal cytoplasm (Gould, 1977; Gould and Mattingly, 1990).

\section{Sorting of myelin proteins}

The distribution of $\mathrm{P}_{0}$ and MAG in Schwann cell perinuclear cytoplasm after MT disassembly has provided insight into how these molecules are sorted and targeted to different surface membranes. Electron microscopic immunocytochemical studies indicate that $\mathrm{P}_{0}$ and MAG are sorted into separate carrier vesicles as they exit the trans-Golgi network. Since laminin is secreted from the Schwann cell plasma membrane (Cornbrooks et al., 1983; Eldridge et al., 1987), it is likely to be sorted into yet another class of transport vesicles. We were unable to test this hypothesis directly, however, because laminin antigenic sites did not survive the stringent fixation used in our electron microscopic studies.
Trans-Golgi network sorting of transmembrane glycoproteins is used by a variety of cells, and separate carrier vesicles specific for apical and basolateral domains have been isolated from Madin Darby canine kidney cells (Wandinger-Ness et al., 1990). Trans-Golgi network sorting delivers proteins to surface membranes more rapidly than does exocytic/endocytic sorting (Simons and Wandinger-Ness, 1990), and would appear to be better suited for the rapid rate of myelination. Our studies did not indicate significant exocytic/endocytic sorting of $\mathrm{P}_{0}$ or MAG in 35-d-old rat peripheral nerve. In electron micrographs of 17-d-old peripheral nerves, however, clathrin-coated pits are frequently associated with myelin membranes (Trapp, unpublished observation), suggesting that exocytic/endocytic sorting may play a role in initial polarization of Schwann cell membranes during early stages of myelination.

The mechanisms responsible for sorting $\mathrm{P}_{0}$ and MAG are unknown, but it is likely that the extracellular and/or cytoplasmic domains of $\mathrm{P}_{0}$ and MAG provide signals for sorting. Both mol- 
ecules are classical type I transmembrane glycoproteins with single transmembrane domains, a glycosylated ectodomain, and a C-terminal cytoplasmic domain (Lemke and Axel, 1985; Salzer et al., 1987). Sorting signals have been identified in both the ectodomain and cytoplasmic domain of other transmembrane glycoproteins, and some proteins may have multiple signals (LeBivic et al., 1991). The extracellular domains of $P_{0}$ and MAG may interact homophilically and form separate clusters that subsequently bud from the trans-Golgi network. This is an attractive hypothesis because $P_{0}$ and MAG are members of the immunoglobulin gene superfamily (Lemke and Axel, 1985; Salzer et al., 1987), a group of adhesion molecules characterized by their ability to interact homophilically. Indeed, the close apposition of the extracellular leaflets $(\sim 2.5 \mathrm{~nm})$ of compact myelin membranes is maintained by homophilic interactions between $P_{0}$ molecules in apposing membranes (Lemke and Axel, 1985; D'Urso et al., 1990; Filbin et al., 1990). To form and maintain this close apposition, membrane glycoproteins with large extracellular domains (such as MAG) must be excluded from compact myelin (Trapp and Quarles, 1982; Trapp et al., 1984). Homophilic interactions between $P_{0}$ molecules in the same lipid bilayer of the trans-Golgi network would effectively sort $P_{0}$ into carrier vesicles and exclude other trans-Golgi network proteins from being targeted to compact myelin.

\section{Targeting, insertion, and stabilization of myelin protein}

Our data are most consistent with the direct insertion of $\mathrm{P}_{0}$-rich carrier vesicles into compact myelin, MAG-rich carrier vesicles into the outer mesaxon, and laminin-rich carrier vesicles into the plasma membrane. These conclusions are based on the following observations. Significant mistargeting of MAG, $P_{0}$, and laminin did not occur after MT disassembly; instead, $\mathrm{P}_{0}$-rich carrier vesicles fused with each other to form myelin-like membranes, and MAG-rich carrier vesicles fused with each other to form mesaxon-like membranes, implying that each class of carrier vesicle contains site- or membrane-specific signals that enhance their fusion with the correct membrane and possibly other signals that prevent fusion with inappropriate membranes. Since membrane fusion is an energy- and calcium-dependent event, active signals are more likely to be responsible for membrane fusion events, whereas electrostatic repulsive forces and hydration layers make fusion with inappropriate membrane unfavorable (Almers, 1990).

Current theories of carrier vesicle-membrane fusion (reviewed in Almers, 1990; Sudhof and Jahn, 1991; White, 1992) describe a series of events that include recognition and docking between a receptor on the carrier vesicle and a ligand on the acceptor membrane, followed by activation of, and a conformational change in, a fusogenic protein. Studies have identified molecules essential for these events and have implicated molecular complexes. Certain molecules, such as the ras family of GTPases, probably participate in fusion events in all cells (Pfeffer, 1992), including Schwann cells (Braun et al., 1990).

Polarization of Schwann cell membrane also requires mechanisms that stabilize proteins within different membrane domains. The Schwann cell plasma membrane, outer mesaxon membrane, and compact myelin are specialized domains of a continuous membrane. Mechanisms must exist, therefore, to obstruct lateral diffusion of proteins between their domains. The plasma membrane and outer mesaxon are separated by junctional complexes that are likely to restrict random diffusion of proteins and some lipids in a manner similar to the junctional com- plexes that separate apical and basolateral domains of epithelial cells (Gumbiner, 1987). Junctional complexes do not separate mesaxon and compact myelin membranes, but specialized cytoskeletal networks (Trapp et al., 1989b; Kordeli et al., 1990) or homophilic interactions similar to those proposed above for sorting $P_{0}$ and $M A G$ in the trans-Golgi network may restrict diffusion of proteins between mesaxon and compact myelin membranes.

The studies described here indicate that MTs are essential for delivery of carrier vesicles along the myelin internode, and suggest that compartment-specific, acceptor-membrane-docking, and/or multiple fusogenic proteins are involved in targeting $\mathrm{P}_{0}$, MAG, and laminin to different membranes. Although much remains to be learned about the molecules and molecular interactions that govern $\mathrm{P}_{0}$ and $\mathrm{MAG}$ targcting, it is likely that specific amino acid sequences in their extracellular and cytoplasmic domains contain important sorting and targeting signals.

\section{References}

Achler C, Filmer D, Merte C, Drenckhahn D (1989) Role of microtubules in polarized delivery of apical membrane proteins to the brush border of the intestinal epithelium. J Cell Biol 109:179-189.

Almers W (1990) Exocytosis. Annu Rev Physiol 52:607-624.

Braun PE, Horvath E, Yong VW, Bernier L (1990) Identification of GTP-binding proteins in myelin and oligodendrocyte membranes. $J$ Neurosci Res 26:16-23.

Bre M-H, Pepperkok R, Hill AM, Levilliers N, Ansorge W, Stelzer EHK, Karsenti E (1990) Regulation of microtubule dynamics and nucleation during polarization in MDCK II cells. J Cell Biol 111: 3013-3021.

Colman DR, Kreibich G, Frey AB, Sabatini DD (1982) Synthesis and incorporation of myelin polypeptide into CNS myelin. J Cell Biol 95:508-608.

Cornbrooks CJ, Carey DJ, McDonald JA, Timpl R, Bunge RP (1983) In vivo and in vitro observations on laminin production by Schwann cclls. Proc Natl Acad Sci USA 80:3850-3854.

D'Urso D, Brophy PJ, Staugaitis SM, Gillespie CS, Frey AB, Stempak JG, Colman DR (1990) Protein zero of peripheral nerve myelin: biosynthesis, membrane insertion, and evidence for homotypic interaction. Neuron 2:449-460.

Eilers U, Klumperman J, Hauri H-P (1989) Nocodazole, a microtubuleactive drug, interferes with apical protein delivery in cultured intestinal epithelial cells (Caco-2). J Cell Biol 108:13-22.

Eldridge CF, Bunge MB, Bunge RP, Wood PM (1987) Differentiation of axon-related Schwann cells in vitro. I. Ascorbic acid regulates basal lamina assembly and myelin formation. J Cell Biol 105:10231034.

Figlewicz DA, Quarles RH, Johnson D, Barbarash GR, Sternberger NH (1981) Biochemical demonstration of the myelin-associated glycoprotein in the peripheral nervous system. J Neurochem 37:749-758.

Filbin MT, Walsh FS, Trapp BD, Pizzey JA, Tennekoon GI (1990) The role of myelin $\mathrm{P}_{0}$ protein as a homophilic adhesion molecule. Nature 344:871-872.

Gilbert T, Le Bivic A, Quaroni A, Rodriguez-Boulan E (1991) Microtubular organization and its involvement in the biogenetic pathways of plasma membrane proteins in Caco-2 intestinal epithelial cells. $\mathbf{J}$ Cell Biol 113:275-288.

Gould RM (1977) Incorporation of glycoproteins into peripheral nerve myelin. J Cell Biol 75:326-338.

Gould RM, Mattingly G (1990) Regional localization of RNA and protein metabolism in Schwann cells in vivo. J Neurocytol 19:285301.

Gould RM, Sinatra RS (1981) Internodal distribution of phosphatidylcholine biosynthetic activity in tcased peripheral nerve fibres: an autoradiographic study. J Neurocytol 10:161-167.

Gould RM, Holshek J, Silverman W, Spivack WD (1987) Localization of phospholipid synthesis to Schwann cells and axons. J Neurochem 48:1121-1131.

Griffiths G, Simons K (1986) The trans Golgi network: sorting at the exit site of the Golgi complex. Science 234:438-443.

Griffiths IR, Mitchell LS, McPhilemy K, Morrison S, Kyriakides E, 
Barrie JA (1989) Expression of myelin protein genes in Schwann cells. J Neurocytol 18:345-352.

Gumbiner B (1987) Structure, biochemistry, and assembly of epithelial tight junctions. Am J Physiol 22:749-758.

Hubbard AL, Stieger B (1989) Biogenesis of endogenous plasma membrane proteins in epithelial cells. Annu Rev Physiol 51:755-770.

Hugon JS, Bennett G, Pothier P, Ngoma Z (1987) Loss of microtubules and alteration of glycoprotein migration in organ cultures of mouse intestine exposed to nocodazole or colchicine. Cell Tissue Res 248: 653-662.

Jacobs JM, Cavanagh JB, Chen FC-K (1972) Spinal subarachnoid injection of colchicine in rats. J Neurol Sci 17:461-480.

Kidd GJ, Andrews SB, 'Irapp BD (1994) Organization of microtubules in myelinating Schwann cells. J Neurocytol, in press.

Kordeli E, Davis JD, Trapp BD, Bennett V (1990) An isoform of ankyrin is localized at nodes of Ranvier in myelinated axons of central and peripheral nerves. J Cell Biol 110:1341-1352.

LeBivic A, Quaroni A, Nichols B, Rodriguez-Roulan F (1990) Biogenic pathways of plasma membrane proteins in Caco-2, a human intestinal epithelial cell line. J Cell Biol 111:1351-1361.

LeBivic A, Sambuy Y, Patzak A, Patil N, Chao M, Rodrigucz-Boulan E (1991) An internal deletion in the cytoplasmic tail reverses the apical localization of human NGF receptor in transfected MDCK cells. J Cell Biol 115:607-618.

Lee C, Ferguson M, Chen LB (1989) Construction of the endoplasmic reticulum. J Cell Biol 109:2045-2055.

Lemke G, Axel R (1985) Isolation and sequence of a cDNA encoding the major structural protein of peripheral myelin. Cell 40:501-508.

Louvard D, Reggio H, Warren G (1982) Antibodies to the Golgi complex and the rough endoplasmic reticulum. J Cell Biol 92:92-107.

Matter K, Brauchbar M, Bucher K, Hauri H-P (1990) Sorting of endogenous plasma membrane proteins occurs from two sites in cultured human intestinal epithelial cells (Caco-2). Cell 60:429-437.

Mostov K, Apodaca G, Aroeti B, Okamoto C (1992) Plasma membrane protein sorting in polarized epithelial cells. J Cell Biol 116:577-583.

Mugnaini E, Olsen KK, Schnapp B, Friedrich VL Jr (1977) Distribution of Schwann cell cytoplasm and plasmalemmal vesicles (caveolae) in peripheral myelin sheaths. An electron microscopic study with thin sections ànd freeze-fracturing. J Neurocytol 6:647-668.

Peters A, Palay SL, Webster H de F (1991) The fine structure of the nervous system: neurons and their supporting cells. New York: Oxford UP.

Pfeffer SR (1992) GTP-binding proteins in intracellular transport Trends Cell Biol 2:41-45.

Rindler MJ, Ivanov IE, Plesken H, Rodriguez-Boulan E, Sabatini DD (1984) Viral glycoproteins destined for apical or basolateral plasma membrane domains transverse the same Golgi apparatus during their intracellular transport in Madin-Darby Canine Kidney cells. J Cell Biol 98:1304-1319.

Rindler MJ, Ivanov IE, Sabatini DD (1987) Microtubule-acting drugs lead to the nonpolarized delivery of the influenza hemagglutinin to the cell surface of polarized Madin-Darby canine kidney cells. J Cell Biol 104:231-241.
Rodriguez-Boulan E, Nelson WJ (1989) Morphogenesis of the polarized epithelial cell phenotype. Science 245:718-725.

Rogalski AA, Singer SJ (1984) Associations of elements of the Golgi apparatus with microtubules. J Cell Biol 99:1092-1100.

Salzer JL, Holmes WP, Colman DR (1987) The amino acid sequences of the myelin-associated glycoproteins: homology to the immunoglobulin gene superfamily. J Cell Biol 104:957-965.

Simons K, Wandinger-Ness A (1990) Polarized sorting in epithelia Cell 62:207-210.

Slot JW, Geuze HJ (1984) Gold markers for single and double immunolabeling of ultrathin cryosections. In: Immunolabeling for electron microscopy (Polak JM, Varndell IM, eds), pp 129-142. Amsterdam: Elsevier.

Sudhof TC, Jahn R (1991) Proteins of synaptic vesicles involved in exocytosis and membrane recycling. Neuron 6:665-677.

Terasaki M, Chen LB, Fujiwara K (1986) Microtubules and the endoplasmic reticulum are highly interdependent structures. J Cell Biol 103:1557-1568.

Tokuyasu KT (1986) Application of cryoultramicrotomy to immunocytochemistry. J Microsc 143:139-149.

Trapp BD, Quarles RH (1982) Presence of the myelin-associated glycoprotein correlates with alterations in the periodicity of peripheral myelin. J Cell Biol 92:877-882

Trapp BD, Itoyama Y, Sternberger NH, Quarles RH, Webster H de F (1981) Immunocytochemical localization of Po protein in Golgi complex membranes and myelin of developing rat Schwann cells. J Cell Biol 90:1-6.

Trapp BD, Quarles RH, Griffin JW (1984) Myelin-associated glycoprotein and myelinating Schwann cell-axon interaction in chronic beta,beta'-iminodipropionitrile neuropathy. J Cell Biol 98:12721278

Trapp BD, Moench T, Pulley M, Barbosa E, Tennekoon G, Griffin JW (1987) Spatial segregation of mRNA encoding myelin-specific proteins. Proc Natl Acad Sci USA 84:7773-7777.

Trapp BD, Bernier L, Andrews SB, Colman DR (1988a) Cellular and subcellular distribution of $2^{\prime}, 3^{\prime}$ cyclic nucleotide $3^{\prime}$ phosphodiesterase and its mRNA in the rat nervous system. J Neurochem 51:859868 .

Trapp BD, Hauer P, Lemke G (1988b) Axonal regulation of myelin protein mRNA levels in actively myelinating Schwann cells. J Neurosei $8: 3515-3521$.

Trapp BD, Andrews SB, Cootauco C, Quarles RH (1989a) The myelinassociated glycoprotein is enriched in multivesicular bodies and periaxonal membranes of actively myelinating oligodendrocytes. J Cell Biol 109:2417-2426.

Trapp BD, Andrews SB, Wong A, O'Connell M, Griffin JW (1989b) Co-localization of the myelin-associated glycoprotein and the microfilament components f-actin and spectrin in Schwann cells of myelinated fibers. J Neurocytol 18:47-60.

Wandinger-Ness A, Bennett MK, Antony C, Simons K (1990) Distinct transport vesicles mediate the delivery of plasma membrane proteins to the apical and basolateral domains of MDCK cells. J Cell Biol 111:987-1000.

White JM (1992) Membrane fusion. Science 258:917-924. 